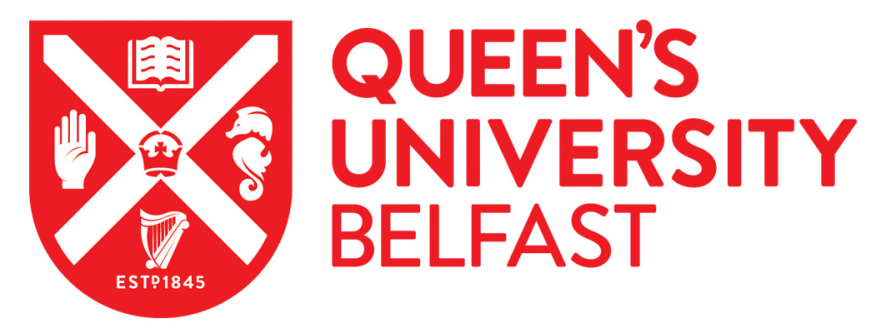

\title{
An accurate account of mass loss during cheese ripening described using the reaction engineering approach (REA) - based model
}

Putranto, A., Woo, M. W., Selomulya, C., \& Chen, X. D. (2017). An accurate account of mass loss during cheese ripening described using the reaction engineering approach (REA) - based model. International Journal of Food Science and Technology. https://doi.org/10.1111/ijfs.13717

Published in:

International Journal of Food Science and Technology

Document Version:

Peer reviewed version

Queen's University Belfast - Research Portal:

Link to publication record in Queen's University Belfast Research Portal

Publisher rights

( 2017 Institute of Food Science and Technology. This work is made available online in accordance with the publisher's policies. Please refer to any applicable terms of use of the publisher.

\section{General rights}

Copyright for the publications made accessible via the Queen's University Belfast Research Portal is retained by the author(s) and / or other copyright owners and it is a condition of accessing these publications that users recognise and abide by the legal requirements associated with these rights.

Take down policy

The Research Portal is Queen's institutional repository that provides access to Queen's research output. Every effort has been made to ensure that content in the Research Portal does not infringe any person's rights, or applicable UK laws. If you discover content in the Research Portal that you believe breaches copyright or violates any law, please contact openaccess@qub.ac.uk. 


\title{
An accurate account of mass loss during cheese ripening described using the reaction engineering approach (REA) - based model
}

\author{
Aditya Putranto $^{1 * *}$, MengWai Woo ${ }^{2}$, Cordelia Selomulya ${ }^{2}$, Xiao Dong Chen ${ }^{3 *}$
}

\author{
${ }^{1}$ School of Chemistry and Chemical Engineering, Queen's University Belfast, David Keir \\ Building, Stranmilis Road, Belfast BT9 5AG, United Kingdom \\ ${ }^{2}$ Department of Chemical Engineering, Monash University, Clayton, Victoria 3800, Australia \\ ${ }^{3}$ School of Chemical and Environmental Engineering, College of Chemistry, Chemical \\ Engineering and Materials Science, Soochow University, Suzhou, Jiangsu Province, PR
} China

\begin{abstract}
A cheese ripening is an important step in cheese making for modifying surface and curd properties. Due to physical, chemical and biological changes, mass loss usually occurs during the process. Although these changes are essential for developing the texture and flavour of cheese, mass loss decreases product yields. A reliable mathematical model is useful to quantify mass loss during cheese ripening so that the processing conditions can be fine-tuned to achieve the desirable throughput. In this study, for the first time, the reaction engineering approach (REA)-based model is applied to model the cheese ripening. The study shows that the REAbased model is accurate to model cheese ripening of Camembert and French smear cheese. In addition, the REA is able to model the cheese ripening under time-varying environmental conditions. For this purpose, the equilibrium activation energy is evaluated according to the corresponding humidity and temperature in each period while the same relative activation energy for ripening under constant environmental conditions is implemented. The REA is a
\end{abstract}


simple yet effective approach to model the simultaneous heat and mass transfer process accompanied by chemical and biological reactions. Considering its effectiveness, the REA can be applied in industrial settings for predicting mass loss during cheese ripening.

Key words: model, cheese ripening, reaction engineering approach (REA), mass loss

Corresponding authors' emails:

*Professor Xiao Dong Chen (xdchen@mail.suda.edu.cn), **Dr. Aditya Putranto (a.putranto@qub.ac.uk)

\section{Introduction}

Cheese-making is usually ended by ripening indicated by physical, chemical and biological changes due to microbial activity. Cheese ripening is essentially breakdown of protein, lipids and carbohydrates which leads to texture modification (Farkye, 2004; Helias and Bernard, 2007). Several ripening agents, covering lactic cultures, milk coagulants, milk enzymes and secondary cultures, contribute to breakdown of these components (Hill, 2017).

Although cheese ripening is important to develop the texture and flavour, mass loss usually occurs during ripening due to physical, biological and chemical changes. Combination of evaporation, production of carbon dioxide and consumption of oxygen contributes to the mass loss (Mirade et al, 2004; Picque et al, 2006; Helias et al, 2007 a,b). Temperature, relative humidity, gas composition and types of microorganisms simultaneously affect the extent of mass loss during ripening (Liu and Puri, 2008). Mass loss is unfavourable since it decreases the product yields. For manufacturing of traditional cheese, weight is sometimes used as the conformity criterion (Gaucel et al, 2012). Depending of the cheese type, the mass loss up to 8\% commonly occur during ripening (Ramet et al, 2000). In addition, due to the difficulty in 
measurement of variables during solid substrate fermentation involved in cheese ripening, the mass loss is often used as an integrative indicator that reflects product evolution and characteristics (Helias et al, 2008).

A reliable mathematical model is useful to account the mass loss during cheese ripening. There are several published mathematical models to describe the cheese ripening which can be classified into empirical and mechanistic-based models. Artificial neural and Bayesian network models are applied to link the processing conditions and moisture content (Funahashi and Horiuchi, 2008, Baudrit et al, 2010). For mechanistic models, diffusion-based models are implemented (Gerla and Rubiolo, 2003; Aldarf et al, 2006; Pajonk et al, 2010). Effective diffusivity was employed to describe the diffusion of water, $\mathrm{NaCl}$ and lactic acid during cheese ripening (Gerla and Rubiolo, 2003).

The above models provide reasonable agreement towards the experimental data. Nevertheless, the empirical models are essentially not physically meaningful since no major phenomena are captured in the models. The diffusion-based models capture well the phenomena but they require a number of experiments followed up by optimization procedures to generate the effective diffusivity function of each species (Gerla and Rubiolo, 2003; Aldarf et al, 2006). The effective models should be able to capture the major phenomena and require minimum number of runs to generate the model parameters.

The reaction engineering approach (REA) is essentially an application of chemical reaction engineering approach to model drying kinetics. Here, the evaporation is represented as zero order activation process and the condensation is modelled as first order without activation process (Chen and Putranto, 2013). To date, the REA has been developed and 
employed a number of heat and mass transfer processes including drying, baking, roasting, water vapor sorption and heat treatment (Putranto et al, 2011 a,b; Putranto and Chen, 2012 a.b; $2014^{\mathrm{a}, \mathrm{b}}$ ). More recently, it has been shown that the REA is not only able to model the evaporation of water but also volatiles (organic components) (Putranto and Chen, 2016). In addition, the REA has been applied to model the solute segregation inside dairy droplets (Putranto et al, 2017)

Due to the applicability of the REA so far, it is worthwhile to develop the REA-based model to represent the mass loss during cheese ripening. Although the REA has been proven to model the several challenging heat and mass transfer processes as described above, it is uncertain whether the REA is applicable to model the mass loss during cheese ripening since chemical and biological reactions may significantly alter the cheese structure. The relative activation energy, as a fingerprint of the REA, may not be able to capture these changes.

In this study, for the first time, the REA is applied to model the mass loss during cheese ripening. It is aimed to evaluate the applicability of the REA framework to describe the mass loss during cheese ripening under controlled and time-varying environmental conditions. The outline of this paper is as follows: firstly, the experimental details are reviewed followed up by development of mathematical model. The relevant discussions are then provided subsequently.

\section{Review of experimental details}

The experimental data for validating the results of modeling are derived from the previously published data (Helias et al, 2007 ${ }^{\text {b }}$, Riahi et al, 2007). For better understanding of the modeling framework, the experimental details are reviewed briefly here. For Camembertcheese ripening, two runs of cheese ripeningare conducted. The first one is undertaken under 
manually adjusted relative humidity while the second one is conducted under automatic controlled relative humidity to ensure the constant relative humidity of $92 \%$. Figure 1 shows the profiles of relative humidity resulted from the manually adjusted humidity. The Camembert cheese is prepared according to protocol described in Leclercq-Perlat (2004). During ripening, the chamber temperature and relative humidity are monitored. The weight of samples and chamber atmospheric composition (concentration of $\mathrm{CO}_{2}$ and $\mathrm{O}_{2}$ ) are also recorded during ripening (Helias et al, 2007 ${ }^{b}$ ). For French smear cheese ripening, the samples are prepared according to the protocol described in Leclercq-Perlat et al (2000). The initial sample weight is $300 \mathrm{~g}$ and the ripening is conducted in the chamber under controlled relative humidity and temperature. In each run, a balance is used to continuously monitor the weight changes (Riahi et al, 2007). The data presented in Riahi et al (2007) and Helias et al (2007 $)$ are used for validating the modelling here. For ripening of French smear cheese, the data presented in Figure 3 of Riahi et al (2007) are used. For ripening of Camembert-cheese under controlled and time-varying ripening conditions, the data presented in Figure5A run 2 and run 1 of Helias et al (2007b) is used, respectively. The figures are converted to the coordinates of time and moisture content by using digitizer software.

\section{Mathematical modeling}

The reaction engineering approach (REA) is employed as a modelling platform in this study. The details of the REA have been presented previously (Chen and Putranto, 2013) and summarised briefly here. Generally, the drying rate of a material can be expressed as:

$$
m_{s} \frac{d X}{d t}=-h_{m} A\left(\rho_{v, s}-\rho_{v, b}\right)
$$

where $m_{s}$ is the dried mass $(\mathrm{kg}), t$ is the time (s), $X$ is the average moisture content on dry basis ( $\mathrm{kg}$ water. $\mathrm{kg}$ dry solids $\left.{ }^{-1}\right), A$ is the surface area $\left(\mathrm{m}^{2}\right), h_{m}$ is the mass transfer coefficient ( $\mathrm{m} \mathrm{s}^{-}$ 
$\left.{ }^{1}\right), \rho_{v, s}$ is the surface water vapor concentration $\left(\mathrm{kg} / \mathrm{m}^{3}\right)$ and $\rho_{v, b}$ is the concentration of water vapor in drying medium $\left(\mathrm{kg} / \mathrm{m}^{3}\right)$.

The surface water vapor concentration $\left(\rho_{v, s}\right)$ can be related against saturated vapor concentration $\left(\rho_{v, s a t}\right)$ by:

$$
\rho_{v, s}=\exp \left(\frac{-\Delta E_{v}}{R T}\right) \rho_{v, s a t}(T)
$$

where $\Delta E_{v}$ is the activation energy $\left(\mathrm{J} \mathrm{mol}^{-1}\right)$ which represents the additional difficulty to remove moisture from the material beyond the free water effect. This $\Delta E_{v}$ is moisture content $(X)$ dependent. $T$ is the sample temperature of the material being dried $(\mathrm{K})$ and $\rho_{v, \text { sat }}$ is the saturated water vapor concentration $\left(\mathrm{kg} / \mathrm{m}^{3}\right)$.

The mass balance (equation (1)) can then be expressed as:

$$
m_{s} \frac{d X}{d t}=-h_{m} A\left[\exp \left(\frac{-\Delta E_{v}}{R T}\right) \rho_{v, s a t}-\rho_{v, b}\right]
$$

The activation energy $\left(\Delta E_{v}\right)$ is determined experimentally by placing the parameters required for equation (3) in its rearranged form:

$$
\Delta E_{v}=-R T \ln \left[\frac{-m_{s} \frac{d X}{d t} \frac{1}{h_{m} A}+\rho_{v, b}}{\rho_{v, s a t}}\right]
$$

The dependence of the activation energy on the moisture content on a dry basis $(X)$ can be normalized as:

$$
\frac{\Delta E_{v}}{\Delta E_{v, b}}=f\left(X-X_{b}\right)
$$

where $f$ is a function of water content difference and $\Delta E_{v, b}$ is the 'equilibrium' activation energy $\left(\mathrm{J} \mathrm{mol}^{-1}\right)$ representing the maximum $\Delta E_{v}$ under the relative humidity and temperature of the drying air. $\Delta E_{v, b}$ can be expressed as: 


$$
\Delta E_{v, b}=-R T_{b} \ln \left(R H_{b}\right)
$$

where $R H_{b}$ is the relative humidity of drying air and $\mathrm{T}_{\mathrm{b}}$ is the drying air temperature $(\mathrm{K})$.

The relative activation energy $\left(\Delta E_{v} / \Delta E_{v, b}\right)$ generated can be applied another drying conditions, provided that the same material and similar initial moisture content, since the relative activation energy would then collapse to a similar profile (Chen and Putranto, 2013).

During cheese ripening, physical, chemical and biological phenomena occur. The physical phenomena is governed by drying which occurred due to the difference in water vapor concentration at the interface of sample and the ambient. The biological and chemical phenomena are mostly determined by production of $\mathrm{CO}_{2}$ and consumption of $\mathrm{O}_{2}$. The generation of other gases (such as aromatic components) are considered to not to play an important role in the mass loss. The production of Camembert-type cheese employs the aerobic pathways in which the respiration quotient is 1, according to the following reaction (Kang and Lee, 1998; Song et al, 2002; Picque et al, 2006):

$$
\mathrm{C}_{6} \mathrm{H}_{12} \mathrm{O}_{6}+6 \mathrm{O}_{2}=>6 \mathrm{CO}_{2}+6 \mathrm{H}_{2} \mathrm{O}
$$

In this study, the production rate of $\mathrm{CO}_{2}$ and consumption rate of $\mathrm{O}_{2}$ are determined based on the measured concentrations of these gases during ripening. This is reasonable since the ripening is undertaken in a closed chamber which ensured that the dynamics of concentrations of $\mathrm{CO}_{2}$ and $\mathrm{O}_{2}$ are only resulted from the exchanges between the atmosphere inside the chamber and the cheese samples (Helias et al, 2007 ${ }^{\mathrm{b}}, 2016$ ).

By implementing the reaction engineering approach (REA), the mass balance of cheese during ripening can be represented as:

$$
m_{s} \frac{d X}{d t}=-h_{m} A\left(\rho_{v, s a t} \exp \left(-\frac{\Delta E_{v}}{R T}\right)-\rho_{v, b}\right)+w_{\mathrm{O}_{2}} r_{O_{2}} A-w_{\mathrm{CO}_{2}} r_{\mathrm{CO}_{2}} A
$$


where $\mathrm{rO}_{2}$ is the consumption rate of oxygen $\left(\mathrm{mol} \cdot \mathrm{m}^{-2} \cdot \mathrm{s}^{-1}\right), \mathrm{rCO}_{2}$ is the production rate of carbon dioxide $\left(\mathrm{mol} \cdot \mathrm{m}^{-2} \cdot \mathrm{s}^{-1}\right)$, wO2 is the molecular weight of oxygen $\left(\mathrm{kg} \cdot \mathrm{mol}^{-1}\right)$ and ${ }^{\mathrm{wCO}}$ is the molecular weight of carbon dioxide $\left(\mathrm{kg} \cdot \mathrm{mol}^{-1}\right)$.

For Camembert-cheese, the relative activation energy $\left(\Delta E_{v} / \Delta E_{v, b}\right)$ is generated from the cheese ripening run under constant environmental conditions (Helias et al, 2007 ${ }^{\mathrm{b}}$ ). The activation energy is evaluated based on equation (4) and divided with the equilibrium activation energy (equation (6)) to result in the relative activation energy (equation (5)). The relative activation energy is then fitted towards the difference in moisture content $\left(X-X_{b}\right)$ based on least square error minimisation method by using solver available in Microsoft Excel ${ }^{\circledR}$. The relative activation energy $\left(\Delta E_{v} / \Delta E_{v, b}\right)$ of Camembert-cheese can be can be written as:

$$
\frac{\Delta E_{v}}{\Delta E_{v, b}}=\left(1-1.113\left(X-X_{b}\right)^{1.313}\right) \exp \left(-1.061\left(X-X_{b}\right)^{3.795}\right)
$$

For the French smear cheese, the relative activation energy $\left(\Delta E_{v} / \Delta E_{v, b}\right)$ is established from the cheese ripening at relative humidity of $99 \%$ and temperature of $12{ }^{\circ} \mathrm{C}$ (Riahi et al, 2007). By using the similar procedures mentioned above, the relative activation energy of French smear cheese can be expressed as:

$$
\frac{\Delta E_{v}}{\Delta E_{v, b}}=\left(1-0.453\left(X-X_{b}\right)^{1.166}\right) \exp \left(0.0157\left(X-X_{b}\right)^{6.722}\right)
$$

The relative activation energy of Camembert and French smear cheese, represented in equations (9) and (10), respectively, is shown in Figure 2. Combination of the relative activation energy with the equilibrium activation energy results in the activation energy which essentially represents the changes in internal cheese structure during ripening. The activation energy is initially zero at the beginning of ripening and keeps increasing during the process as the difficulty to remove the moisture from the samples increases. When the equilibrium 
condition is achieved, the equilibrium activation energy is attained and the relative activation energy is one.

The heat balance during the cheese ripening can be expressed as:

$$
\frac{d\left(m C_{p} T\right)}{d t} \approx h A\left(T_{b}-T\right)-h_{m} A\left(\rho_{v, s a t} \exp \left(-\frac{\Delta E_{v}}{R T}\right)-\rho_{v, b}\right) \Delta H_{V}+0.5\left(r_{O_{2}}+r_{C_{2}}\right) A \Delta H_{\text {respiration }}
$$

where $m$ is the sample mass $(\mathrm{kg}), C_{p}$ is the sample heat capacity $\left(\mathrm{J} \mathrm{kg}^{-1} \cdot \mathrm{K}^{-1}\right), h$ is the heat transfer coefficient $\left(\mathrm{W} \cdot \mathrm{m}^{-2} \cdot \mathrm{K}^{-1}\right), \Delta H_{v}$ is the vaporization heat of water $\left(\mathrm{J}^{\mathrm{kg}} \mathrm{kg}^{-1}\right)$ and $\Delta H_{\text {respiration }}$ is the respiration heat $\left(\mathrm{J} \cdot \mathrm{mol}^{-1}\right)$.

In order to yield the profiles of mass and temperature during Camembert cheese ripening, equations (8), (9) and (11) are solved simultaneously in conjunction with the equilibrium activation energy (equation (6)). Similar approach is used for modelling French smear cheese ripening but the relative activation energy shown in equation (10) is employed. For modelling the mass loss of cheese ripening under time-varying relative humidity, the corresponding humidity in each ripening period is employed in the mass balance (equation (8)). The relative activation energy, implemented for the ripening under constant environmental conditions, is used here and combined with the equilibrium activation energy (equation (6)) evaluated according to the corresponding humidity and temperature in each period.

The results of REA-based modelling are also benchmarked towards the modelling of Helias et al $\left(2007^{\mathrm{b}}\right)$ and Riahi et al (2007). Helias et al $\left(2007^{\mathrm{b}}\right)$ implemented ordinary differential equation to describe the mass changes of samples during ripening in which empirical expression of evaporation is used. Coupling the mass and heat balances result in the profiles of mass and temperature during ripening. The transport parameters are also tuned to 
match with the experimental data. In addition, Riahi et al (2007) employed an empirical model to describe the ripening. In the model (Riahi et al (2007), evaporation is treated as the difference of moisture content at particular time and the one at the equilibrium where the empirical constants are employed to describe the proportionality (Riahi et al, 2007).

\section{Results and Discussion}

Figure 3 shows the mass profiles of Camembert cheese during ripening under controlled relative humidity and temperature (Figure 5 runs 2 in Helias et al $\left(2007^{\mathrm{b}}\right)$ ). The REA-based model matches very well with the experimental data $\left(R^{2}\right.$ of 0.998$)$. The model seems to be accurate to project the mass profiles duringripening. Benchmarks towards the other model (Helias et al, 2007 ${ }^{\mathrm{b}}$ ) shows that the REA-based model gives a closer agreement towards the experimental data. The very slight overestimations of the mass on Figure 3 could be because of the experimental errors in measurement of the concentration of oxygen and carbon dioxide inside the chamber. Although biochemical reactions, resulted from respiration, occur during the ripening, the process is predicted well by the REA. While the REA predicts well the mass during whole ripening process, the other model underestimates the mass after 10 days of ripening. The REA accuracy could be because the relative activation energy captures well the changes of sample structure due to physical, chemical and biological changes during ripening. The REA-based model is applicable to model the mass loss during ripening of Camembert cheese under controlled/constant environmental conditions.

In order to investigate the applicability of the REA-based model to model the mass loss during ripening of another type of cheese, the REA is applied to model the mass loss during ripening of French smear cheese under various conditions. Figure 4 describes the results of modeling of mass loss of French smear cheese ripening at constant environmental conditions 
i.e. relative humidity of $85 \%$ and temperature of $12{ }^{\circ} \mathrm{C}$ (Figure 3 in Riahi et al (2007)). The REA-based model yields a good agreement towards the experimental data ( $R^{2}$ of 0.997$)$. Compared to the other model implemented by Riahi et al (2007) (labelled as "RH 85\% Riahi et al (2007)" in Figure 4), the REA gives closer agreement towards the experimental data. The overestimation of mass profiles during before $6 \times 10^{5} \mathrm{~s}$ is not shown by the REA-based model. Similarly, Figure 4 indicates that the REA-based model predict well the mass profiles during French smear cheese ripening at relative humidity of 99\% (Figure 3 in Riahi et al (2007)). Benchmarks towards the empirical model implemented by Riahi et al (2007) (labelled as "RH 99\% Riahi et al (2007)" in Figure 4) indicate that the REA provides comparable results. In order to see the robustness of the REA-based model, the model is also applied to model the mass loss during French smear cheese ripening at relative humidity of $83 \%$ and $87 \%$ whose results are shown in Figure 5. The decrease of relative humidity results in higher mass loss during ripening which is because of the higher driving force of evaporation.

The REA-based model is accurate and robust to model the mass loss during ripening of French smear cheese under various conditions. The capability of the REA is likely because of the accurate relative activation energy. It is emphasised here that the relative activation energy of French smear cheese is generated from the ripening run at relative humidity of $99 \%$ and temperature of $12{ }^{\circ} \mathrm{C}(($ Figure 3 in Riahi et al (2007))) shown in equation (10). By using the same equation (i.e. equation (10)), the mass loss during ripening at other conditions can be predicted well. This is as opposed to the modelling implemented by Riahi et al (2007) which requires several experiments followed up by optimisation in order to generate the empirical constants dependent on the ripening conditions. This highlights the effectiveness of the REA in terms of experimentations and mathematical procedures. 
For cheese ripening under time-varying external conditions, as shown in Figure 6, the REA-based model is also accurate to model the mass loss. The good agreement towards the experimental data is indicated by $R^{2}$ of 0.995 . Benchmarks against the other model (Helias et al, $2007^{\text {b }}$ ) indicate that the REA-based model give comparable results. It is highlighted that the relative activation energy $\left(\Delta E_{v} / \Delta E_{v, b}\right)$ used to describe the mass loss during ripening under controlled conditions (i.e. equation (9)) is implemented here. In order to incorporate the effects of time-varying relative humidity, the equilibrium activation energy $\left(\Delta E_{v, b}\right)$ is evaluated at the corresponding humidity and temperature in each period by using equation (6). The REA-based model is able to model the mass loss during ripening under time-varying conditions. This may be because of the flexibility of the activation energy function. Combined with the relative activation energy $\left(\Delta E_{v} / \Delta E_{v, b}\right)$, the equilibrium activation energy $\left(\Delta E_{v, b}\right)$ yields unique activation energy $\left(\Delta E_{v}\right)$ relationships which seems to be able to capture the effects of changing external conditions and reflect these to the internal cheese structure. Compared to the modelling by Helias et al $\left(2007^{b}\right)$, the REA-based model is more effective. Helias et al $\left(2007^{b}\right)$ modifies the heat and mass transfer correlations in order to allow the model to predict the mass loss under time-varying relative humidity. On the other hand, for the REA-based model, the same relative activation energy function as the one for predicting mass loss under controlled ripening conditions is implemented.

The applicability of the REA to predict the mass loss during changing environmental conditions follows the accuracy of the REA to model drying under time-varying external conditions (Putranto et al, 2011 , Putranto and Chen, 2012 a,b $)$. However, the mass loss during cheese ripening is more complicated as it involves chemical and biological reactions. The applicability of the REA here may indicate that the relative activation energy can capture the alterations of cheese structure as a result of these complex reactions. 
The temperature profiles of Camembert cheese ripening under controlled and timevarying relative humidity are shown in Figure 7. In both cases, the temperature of the samples jumped into the chamber temperature very quickly which may be due to the intense heat transfer from the surrounding environment to the samples. Some very slight wiggles are observed in the temperature profiles of the samples undergoing ripening undertime-varying conditions. This is reasonable since the variations in relative humidity may alter the evaporation rate which consequently modifiesthe amount of heat removed from the sample. Although the temperature profiles seem to be relatively constant during ripening, it is not recommended to assume isothermal condition during the ripening since moisture removal which occurs during ripening is essentially simultaneous heat and mass transfer process. The heat supplied by the surrounding air to the sample is used for evaporating the water and raising the sample temperature. In this study, the relatively constant temperature may be because of the low surrounding air temperature and low drying rate due to low initial moisture content.

Based on the study here, it is proven that the REA-based model can describe the mass loss during ripening very well. In terms of experimentations, the REA is very effective as the relative activation energy generated from one particular run can be used to predict the mass loss during ripening at other conditions including the ones under time-varying conditions. This prevents the necessity to undertake a series of experiments under different conditions followed up by optimisation procedures. The REA-based model is simple with respect to computational time since it is formulated in ordinary differential equation. Nevertheless, the major physics of mass loss during ripening is captured well by the REA-based model. 
Considering its effectiveness, the REA-based model can be used in industrial settings to assist in predicting mass loss during ripening. For designing new facilities of cheese ripening, the REA can contribute to describe the flow-field inside the ripening chamber as a result of water removal. For this purpose, the REA can be implemented in Computational Fluid Dynamics (CFD) simulation in which the REA is coupled with a set of equations of conservation of the drying air. The REA-based model can also be used tofine-tune the ripening processto yield desirable cheese properties by coupling the REA-based model with the equations relating the moisture content and temperature with the textural and sensory properties (Tan and Zhou, 2003; 2008; Haque et al, 2013).

\section{Conclusions}

In this study, the reaction engineering approach (REA)-based model is developed to model the mass loss during cheese ripening. The REA is coupled with the heat balance and the chemical and biological reactions to describe the mass loss during ripening under controlled/constant and time-varying environmental conditions. The REA-based model is accurate to describe the mass loss during cheese ripening. This accuracy is likely attributed by the accurate and flexible activation energy which describes the internal changes of cheese structure during ripening. The effects of complex chemical and biological reactions are incorporated in the relative activation energy. While the REA modelling is simple, the REA can capture major physics of water removal during ripening. In industrial settings, the REAbased model can be used as a basis for designing cheese ripening process with the desirable quality. 


\section{References}

Aldarf, M., Fourcade, F., Amrane, A., Pringent, Y., 2006. Substrate and metabolite diffusion within model medium for soft cheese in relation to growth of Penicilliumcamembertii. Journal of Industrial Microbiology and Biotechnology 33, 685-692.

Baudrit, C., Sicard, M., Wuillemin, P.H., Perrot, N., 2010. Towards a global modelling of the Camembert-type cheese ripening process by couplingheterogeneous knowledge with dynamic Bayesian networks. Journal of Food Engineering 98, 283-293.

Chen, X.D., Putranto, A., 2013. Modeling Drying Processes: a Reaction Engineering Approach, Cambridge University Press, United Kingdom (ISBN: 978-1107012103).

Farkye, N.Y. 2004. Cheese technology. International Journal of Dairy Technology 57, 91-98.

Funahashi, H., Horiuchi, J., 2008. Characteristics of churning process in continous butter manufacture and modeling using an artificial neural network. International Dairy Journal 18, 323-328.

Gaucel, S., Guillemin, H., Corrieu. G., 2012. A generalised model for cheese mass loss determination during ripening. Journal of Food Engineering 110, 109-116.

Gerla, P.E., Rubiolo, A.C., 2003. A model for determination of multicomponent diffusion coefficients in foods. Journal of Food Engineering 56, 401-410.

Haque, M.A., Putranto, A., Aldred, P., Chen, J., Chen, X.D., Adhikari, A. 2013, Drying and denaturation kinetics of whey protein isolate (WPI) during convective air drying process. Drying Technology31, 1532-1544.

Helias, A., Bernard, O. 2007ª . Assessing the main reactions in bioprocess: applications in cheese ripening. IFAC Proceedings 40, 187-194. 
Helias, A., Mirade, P.S., Corrieu, C., 2007 . Modeling of camembert-type cheese mass loss in a ripening chamber: main biological and physical phenomena. Journal of Dairy Science $90,5324-5333$.

Helias, A., Trelea, I.C., Corrieu, G., 2008. Assessment of respiratory activity during surfacemould cheese ripening. Journal of Food Engineering 85, 632-638.

Hill, A.R., 2017. Cheese Technology. Dairy Science and Technology Education Series, University of Guelph, Canada. Accessed

onlinehttps://www.uoguelph.ca/foodscience/book-page/ripening-processes-chemicaland-physical-changes

Kang, J. S., Lee. D.S. ,1998. A kinetic model for transpiration of fresh produce in a controlled atmosphere. Journal of Food Engineering 35, 65-73.

Leclercq-Perlat, M. N., Buono, F., Lambert, D., Latrille, E., Spinnler, E., Corrieu. G., 2004. Controlled production of Camembert-type cheeses. Part I: Microbiological and physicochemical evolutions. Journal of Dairy Research 71, 346-354.

Leclercq-Perlat, M.N., Oumer, A., Bergere, J.L., Spinnler, H.E., Corrieu, G., 2000. Behavior of Brevibacterium linens and Debaryomyceshansenii as ripening flora in controlled production of smear soft cheese from reconstituted milk: Growth and substrate consumption. Journal of Dairy Science 83, 1665-1673.

Liu, S., Puri, V.M., 2008. pH spatial distribution model during ripening of Camembert cheese. LWT 41, 1528-1534.

Mirade, P. S., T. Rougier, A. Kondjoyan, J. D. Daudin, D. Picque, Corrieu. G., 2004. Caracte'risationexpe'rimentale de l'ae'raulique d'un ha^ loir de fromagerie et des echanges air-produit. Lait 84, 483-500.

Pajonk, A. Saurel, S., Andrieu, J., Laurent, P., Blanc. D., 2003. Heat transfer study and modeling during Emmental ripening. Journal of Food Engineering 57, 249-255. 
Picque, D., Leclercq-Perlat, M.N., Corrieu. G., 2006. Effect of atmospheric composition on respiratory behavior, weight loss and appearance of Camembert-type cheeses during chamber ripening. Journal of Dairy Science 89, 3250-3259.

Putranto, A., Chen, X.D., 2012 ${ }^{\mathrm{a}}$. Roasting of barley and coffee modeled using the lumpedreaction engineering approach (L-REA). Drying Technology 30, 475-483.

Putranto, A., Chen, X.D., 2012 .Modeling of intermittent drying of wood under rapidly varying temperature and humidity conditions using the lumped reaction engineering approach (L-REA). Drying Technology 30, 1658-1665.

Putranto, A., Chen, X.D., 2014ª . Examining the suitability of the reaction engineering approach (REA) to modelling localevaporation/condensation rates of materials with various thicknesses.Drying Technology32, 208-221.

Putranto, A., Chen, X.D., 2014 ${ }^{\mathrm{b}}$. Modeling of water vapor sorption process by employing the reaction engineering approach (REA). Separation and Purification Technology 122, 456-461.

Putranto, A., Chen, X.D., Webley, P.A., 2011 ${ }^{\text {a }}$ Simple, accurate and robust modeling of various systems of drying of foods and biomaterials: a demonstration of the feasibility of the reaction engineering approach (REA). Drying Technology 29, 1519-1528.

Putranto, A., Chen, X.D., Zhou, W., 2011 ${ }^{\mathrm{b}}$. Modeling of baking of cake using the reaction engineering approach (REA). Journal of Food Engineering 105, 306-311.

Putranto, A., Chen, X.D., Devahastin, S., Xiao, Z., Webley, P.A., 2011 ${ }^{\mathrm{c}}$. Application of the reaction engineering approach (REA) to model intermittent drying under time-varying humidity and temperature. Chemical Engineering Science 66, 2149-2156.

Putranto, A., Chen, X.D., 2016. Drying of a system of multiple solvents: modeling by the reaction engineering approach (REA). AIChE Journal 62, 2144-2153. 
Putranto, A., Foerster, M., Woo, M.W., Chen, X.D., Selomulya, C., 2017. A continuumapproach modelling of surface composition and ternary component distribution inside low fat milk emulsions during single droplet drying. AIChE Journal (accepted, in press). DOI: $10.1002 /$ aic. 15657.

Ramet, J. P. 2000. Comparing ripening technology of the various types of cheese. In: Cheesemaking, from Science to Quality Assurance. Edited by A. Eck and J. C. Gillis, Lavoisier Publishing, Paris, France.

Riahi, M.H., Trelea, I.C., Leclercq-Perlat, M.N., Picque, D., Corrieu, G., 2007. Model for changes in weight and dry matter during the ripening of a smear soft cheese under controlled temperature and relative humidity. International Dairy Journal 17, 946-953.

Saurel, R., Pajonk, A., Andrieu, J., 2004. Modelling of French emmental cheese water activity during salting and ripening period. Journal of Food Engineering 63, 163-170.

Song, Y., Vorsa, N., Yam. K.L. 2002. Modeling respiration-transpiration in a modified atmosphere packaging system containingblueberry. Journal of Food Engineering $53,103-109$

Stepaniak, L., 2004. Dairy Enzymology. International Journal Dairy Technology 57, 153171.

Tan, A., Zhou, W. 2003. Colour development of bread during baking. Proceedings of the 8th ASEAN Food Conference (pp. 488-492) (Hanoi, Vietnam).

Tan, M. Y., Zhou, W. 2008. Modelling of bread crust colour development during baking. Food Manufacturing Efficiency, 2, 9-15. 


\section{Legends to Figures}

The figures describe dynamic of relative humidity during ripening, relative activation energy as fingerprints of the REA, profiles of mass loss and temperature during ripening of Camembert-cheese and French smear cheese.

Figure 1 shows the dynamic of relative humidity during ripening of Camembert-cheese under manually adjusted humidity

Figure 2 describes the relative activation energy shown in equations (9) and (10).

Figure 3 represents the profiles of mass loss during ripening of Camembert under controlled relative humidity cheese modelled using the REA benchmarked to the modelling by Helias et al $\left(2007^{b}\right)$.

Figure 4 shows the profiles of mass loss during ripening of French smear cheese modelled using the REA compared to the modelling by Riahi et al (2007).

Figure 5 represents the sensitivity of the REA model to the relative humidity

Figure 6 describes the profiles of mass loss during ripening of Camembert cheese under timevarying relative humidity modelled using the REA benchmarked to the modelling by Helias et al $\left(2007^{\mathrm{b}}\right)$.

Figure 7 shows the profiles of sample temperature during ripening of Camembert cheese 